\title{
A prospective study comparing the efficacy of intravenous clonidine with intravenous dexmedetomidine in attenuating the haemodynamic stress response during laryngoscopy and endotracheal intubation
}

\author{
Chhaya M Suryawanshi ${ }^{1}$, Rajan Kumar,", Rachna Wadhwa ${ }^{3}$ \\ ${ }^{1}$ Professor, Dept. of Anaesthesia, D.Y. Patil Medical College Hospital and Research Centre, Pimpri, Dr. D.Y. Patil Vidyapeeth, \\ Pune, Maharashtra, ${ }^{2}$ Attending Consultant, Dept. of Neuro Anaesthesia, Paras Hospital, Gurugram, Haryana, ${ }^{3}$ Associate \\ Professor, Dept. of Anaesthesiology and Critical Care, G.B. Pant Hospital (GIPMER), New Delhi, India
}

*Corresponding Author:

Email: dr.rajankumar07@gmail.com

Received: $12^{\text {th }}$ January, 2018

Accepted: $6^{\text {th }}$ March, 2018

\begin{abstract}
Introduction: Laryngoscopy and endotracheal intubation are noxious stimuli capable of producing tachycardia, arrhythmias and hypertension. This study was being done to compare the effectiveness of a pre-induction dose of clonidine with dexmedetomidine administered by intravenous infusion inattenuating the haemodynamic stress responses resulting from laryngoscopy and endotracheal intubation.

Materials and Methods: Sixty adult patients included in this study were randomly divided into two groups, namely, Group A (Clonidine $4 \mathrm{mcg} / \mathrm{kg}$ ) \& Group B (Dexmedetomidine $1 \mathrm{mcg} / \mathrm{kg}$ ) using computer generated random allocation chart and haemodynamic parameters were analyzed and recorded quantitatively from preoperative period to 30 mins post - intubation period.

In the immediate post operative period and 2 hours after surgery, patient's recovery was assessed with ALDRETE recovery score and BRUSSEL'S sedation score.

Results: Mean heart rate showed fall following dexmedetomidine or clonidine infusion (19\% and $23 \%$ respectively from the baseline) which was clinically significant in clonidine group but was statistically not significant in both the groups ( $p>0.05$ ), while the increase in Mean heart rate following intubation was $8 \%$ and $10 \%$ respectively. In the current study, there was fall in blood pressure following infusion of study drug which was clinically not significant. Following tracheal intubation, maximal average increase was $5 \%$ in systolic and $3 \%$ in diastolic blood pressure in dexmedetomidine group, as compared to clonidine group in which, it was $6 \%$ and $4 \%$, respectively. Isoflurane consumption, propofol requirement and opioid requirement throughout the intraoperative period was reduced in both the Groups.

Aldrete recovery score and Brussels sedation score were calculated and found better in group B as compared to group A. Patients were sedated but arousable.

Conclusion: Based on our study we conclude that both clonidine and dexmedetomidine are equally effective in attenuating the pressor response caused by laryngoscopy and tracheal intubation.
\end{abstract}

Keywords: Dexmedetomidine, Clonidine, Laryngoscopy, Aldrete score, Brussels score.

\section{Introduction}

Laryngoscopy and endotracheal intubation frequently induces a transient cardiovascular stress response characterised by hypertension and tachycardia due to reflex sympathetic stimulation. ${ }^{1}$

Usually these transient changes have no deleterious consequences in healthy individuals, but they may be fatal in some patients with pre-existing hypertension, coronary artery disease, cerebrovascular diseases, myocardial infarction and thyrotoxicosis. ${ }^{2,3}$

Various pharmacological approaches including agents like lignocaine, beta blockers, calcium channel blockers, vasodilators like sodium nitroprusside and nitroglycerine, synthetic narcotics like alfentanyl and Inhalational agents have been used to prevent the pressor response..$^{4-8}$

Alpha 2-adrenoceptor agonists like clonidine and dexmedetomidine are being increasingly used in anaesthesia and critical care.

Clonidine is a centrally acting selective partial alpha 2-adrenergic agonist (220:1 alpha 2 to alpha 1$).{ }^{9-}$ 12

Dexmedetomidine is a highly selective, specific, and potent alpha 2-adrenergic agonist (1,620:1 alpha 2 to alpha 1), especially for the alpha 2 A. Compared with clonidine it is eight times more selective for alpha2. It provides anaesthetic sparing effects, anxiolysis, sedation and analgesia without respiratory depression. ${ }^{13-16}$

This study was being done to compare the effectiveness of a pre-induction dose of clonidine with dexmedetomidine administered by intravenous infusion inattenuating the haemodynamic stress responses resulting from laryngoscopy and endotracheal intubation. To assess and compare the recovery and sedation score of patients in both groups, after completion of surgery.

To find out and compare the side effects if any in the use of these drugs during this study. 


\section{Materials and Methods}

Sixty adult patients aged between 18 and 55 years in American Society of Anaesthesiologists (ASA) physical status I and II, undergoing elective surgeries under standard general anaesthesia were included in this prospective, randomized, controlled study after obtaining the Institutional Ethics Committee approval prior to commencement of study.

All Patient's with Uncontrolled diabetes mellitus, uncontrolled hypertension, cardiac abnormalities (Congestive heart failure, Coronary artery disease, any degree of heart block, bradycardia, patient on preoperative $\beta$-blocker therapy and cardiogenic shock), Respiratory (Bronchial asthma), renal or cerebral disease and patients with predictably difficult airway were excluded from the study.

After obtaining informed and written consent from every case selected for the study, all the patient's were randomly divided into two groups using computer generated random allocation chart.

Group A: Inj. Clonidine (I.V. infusion) - $4 \mathrm{mcg} / \mathrm{kg}$

Group B: Inj. Dexmedetomidine (I.V. infusion)- 1 $\mathrm{mcg} / \mathrm{kg}$.

All patients were thoroughly evaluated preoperatively and Base line vital parameters such as heart rate (HR), systolic blood pressure (SBP), diastolic blood pressure (DBP), mean arterial pressure (MAP), $\mathrm{SPO}_{2}$, Resp. Rate and ECG were recorded $\left(\mathrm{T}_{0}\right)$

The drug to be studied was administered intravenously, 15 mins prior to induction. The drug clonidine $4 \mathrm{mcg} / \mathrm{kg}$ or dexmedetomidine $1 \mathrm{mcg} / \mathrm{kg}$ was diluted and infused slowly over a period of 10 mins. The vital parameters were recorded once again $\left(\mathrm{T}_{1}\right)$.

Patients were premedicated with Injection Butorphenol $(0.03 \mathrm{mg} / \mathrm{kg})$ and Injection Glycopyrollate $(0.004 \mathrm{mg} / \mathrm{kg})$ intravenously $5 \mathrm{mins}$ prior to induction the vital parameters were recorded once again. $\left(\mathrm{T}_{2}\right)$.

Patients were preoxygenated with $100 \%$ oxygen for 3 minutes.

This was followed by induction with Injection Propofol $(2 \mathrm{mg} / \mathrm{kg})$ given slowly till the loss of eyelash reflex. The choice of muscle relaxant was Injection Rocuronium $(0.6 \mathrm{mg} / \mathrm{kg})$. Oxygen and nitrous oxide was started (50\% each). The vital parameters were recorded once again $\left(\mathrm{T}_{3}\right)$.

Laryngoscopy and tracheal intubation was attempted after 90 seconds followed by, recording of the vital parameters $\left(\mathrm{T}_{4}\right)$.

Once the endotracheal intubation was achieved, the surgery was allowed to proceed after fixing the endotracheal tube and confirming bilateral air entry and giving positive pressure ventilation. The periodic monitoring of the vital parameters were carried out at 0 , $1,3,5,10,15,30$ mins, post intubation.

Anaesthesia was maintained with $65 \%$ nitrous oxide and $35 \%$ oxygen mixture along with isoflurane $0.4 \%-0.6 \%$ in Bain's breathing circuit and controlled ventilation with intermittent doses of rocuronium as and when required by the patient.

Patient's were monitored for side effects of study drug, if any during the course of intubation and in the period following intubation.

At the end of surgery patient's were reversed with Inj. Glycopyrrolate $0.008 \mathrm{mg} / \mathrm{kg}$ along with inj. Neostigmine methyl sulphate $0.05 \mathrm{mg} / \mathrm{kg}$ intravenously. Patient's were finally extubated and then shifted to the recovery room.

In the immediate post operative period and 2 hours after surgery patient's recovery was assessed, Aldrete recovery ${ }^{24}$ score and BRUSSEL'S sedation score ${ }^{25}$ were assessed and recorded.

\section{Statistical Analysis}

At the end of the study all results obtained were statistically analysed and compared.

Statistical analysis was done by SPSS software version 17 by using $Z$ test. $P$ value less than 0.05 was considered as significant and $\mathrm{P}$ value less than 0.001 as highly significant.

\section{Results}

In the current study we have assessed the efficacy of intravenous dexmedetomidine and clonidine in attenuating haemodynamic stress response to laryngoscopy and tracheal intubation and following were the observations.

Both groups were comparable with respect to their demographic profiles like age, body weight and sex with $(\mathrm{P}>0.05)$, statistically not significant.

Mean heart rate, Mean Systolic blood pressure, Mean Diastolic blood pressure and Mean Arterial blood pressure were analyzed quantitatively within groups for each stage from preoperative to $30 \mathrm{mins}$ post intubation.

Mean and Standard deviation of heart rate was calculated at each interval.

Mean heart rate was highest in Group B 78.7 (S.D. \pm 14.39 ), which showed fall following administration of study drug i.e.63.6 (S.D. \pm 13.55), while Group A showed fall in heart rate from 77.53 (S.D. \pm 9.9) to 58.67 (S.D. \pm 7.86 ). Fall in the heart rate following infusion of study drug was not significant in both the groups ( $p>0.05$ ).

Group A showed increase in Mean heart rate following intubation from 62.9(S.D. \pm 9.43) at T3 (pre - intubation) to 69.37 (S.D. \pm 12.38 ) at T4 (post intubation) and similar trend was seen in Group B following intubation from 70 (S.D. \pm 12.78 ) at T3 to 75.6 (S.D. \pm 12.74 ) at T4.

The $\mathrm{Z}$ value was $2.45,2.44$, which was significant (p< 0.05) at T3 (pre - intubation) and at $1 \mathrm{~min}$ following intubation. (Table 1) 
Mean systolic blood pressure showed fall in Group A 115.77 (S.D. \pm 9.81), as well as in Group B 121.43 (S.D. \pm 11.56 ), following infusion of study drug.

There was a transient increase in the, Mean systolic pressure following laryngoscopy and tracheal intubation in Group A from 112.83 (S.D. \pm 10.11 ) at T3 (pre - intubation) to 118.8 (S.D. \pm 9.47) at T4 (post intubation) and in Group B from 119 (S.D. \pm 13.25) at T3 to 124.93 (S.D. \pm 10.26 ) at T4.

The $\mathrm{Z}$ value was $2.04,2.11,2.03,2.41,2.46$ and 2.27 which was significant $(\mathrm{p}<0.05)$ at $\mathrm{T} 1, \mathrm{~T} 2, \mathrm{~T} 3, \mathrm{~T} 4$, $1 \mathrm{~min}$ and $15 \mathrm{~min}$ intraoperatively. (Table 2)

Mean Diastolic blood pressure showed fall in Group A 76.53 (S.D. \pm 6.44 ), as well as in Group B 77.27 (S.D. \pm 6.87 ), following infusion of study drug.

There was a transient increase in the Mean Diastolic pressure following laryngoscopy and tracheal intubation in Group A from 73.93 (S.D. \pm 10.3 ) at T3 (pre - intubation) to 76.53 (S.D. \pm 7.86 ) at T4 (post intubation) and in Group B from 78.03 (S.D. \pm 12.3 ) at T3 to 79.77 (S.D. \pm 11.33 ) at T4.

The $\mathrm{Z}$ value was 2.04 which was significant $(\mathrm{p}<$ 0.05 ) at 3 mins intraoperatively. (Table 3)

Mean arterial blood pressure showed fall in Group A 89.63 (S.D. \pm 6.84 ), as well as in Group B 92.4 (S.D. \pm 7.99 ), following infusion of study drug.

There was a transient increase in the, Mean arterial pressure following laryngoscopy and tracheal intubation in Group A from 86.5 (S.D. \pm 9.35) at T3 (pre - intubation) to 91.56 (S.D. \pm 8.24 ) at T4 (post intubation) and in Group B from 92.3 (S.D. \pm 12.2) at $\mathrm{T} 3$ to 95.4 (S.D. \pm 10.63 ) at T4.

The $\mathrm{Z}$ value was $2.03,2.06,2.05,2.06,2.16$ which was significant $(\mathrm{p}<0.05)$ at T2, T3. 1 min, 3 mins and 5 mins intraoperatively. (Table 4)

Mean Aldrete score at the end of surgery in group A was 8.47 (S.D. \pm 0.57 ) and in group B was 8.93 (S.D. \pm 0.52). Mean score within group was analyzed quantitatively and $\mathrm{Z}$ value was 3.27 which is statistically significant. $(p<0.001)$.Mean Aldrete score 2 hrs after surgery in recovery room in group A was 9.87 (S.D. \pm 0.35 ) and in group B was 9.93 (S.D. \pm 0.25). Mean score within group was analyzed quantitatively and $\mathrm{Z}$ value was 0.85 which is statistically not significant. ( $p>0.05$ ). (Table 5, Bar-Diagram 1)

Mean Brussel's score at the end of surgery in group A was 3.9 (S.D. \pm 0.4 ) and in group B was 4.13 (S.D. \pm 0.35). Mean score within group was analyzed quantitatively and $\mathrm{Z}$ value was 2.37 which is statistically significant. $(\mathrm{p}<0.05)$.

Mean Brussel's score $2 \mathrm{hr}$ after surgery in recovery room in group A was 4.87 (S.D. \pm 0.35 ) and in group B was 4.9 (S.D. \pm 0.31). Mean score within group was analyzed quantitatively and $\mathrm{Z}$ value was 0.39 which is statistically not significant. ( $p>0.05$ ). (Table 6, BarDiagram 2)

Table 1: Comparison of heart rate in study groups

\begin{tabular}{|c|c|c|c|c|c|c|c|}
\hline \multirow{2}{*}{\multicolumn{2}{|c|}{ Heart Rate (min) }} & \multicolumn{2}{|c|}{ Group A $(n=30)$} & \multicolumn{2}{|c|}{ Group B $(n=30)$} & \multirow[t]{2}{*}{ Z Value } & \multirow[t]{2}{*}{ P Value } \\
\hline & & Mean & SD & Mean & SD & & \\
\hline \multicolumn{2}{|c|}{ Baseline (T0) } & 77.53 & 9.89 & 78.7 & 14.39 & 0.37 & $>0.05$ \\
\hline \multicolumn{2}{|c|}{$\begin{array}{l}\text { Immediate after infusion of } \\
\text { drug (T1) }\end{array}$} & 58.67 & 7.86 & 63.6 & 13.55 & 1.72 & $>0.05$ \\
\hline \multicolumn{2}{|c|}{ After pre-medication (T2) } & 60.47 & 10.42 & 66.03 & 12.76 & 1.85 & $>0.05$ \\
\hline \multicolumn{2}{|c|}{ Pre intubation (T3) } & 62.9 & 9.43 & 70 & 12.78 & 2.45 & $<0.05$ \\
\hline \multirow{7}{*}{$\begin{array}{l}\text { Post } \\
\text { intubation }\end{array}$} & T4 (at $0 \mathrm{~min}$ ) & 69.37 & 12.38 & 75.6 & 12.74 & 1.92 & $>0.05$ \\
\hline & At $1 \mathrm{~min}$ & 69.23 & 9.13 & 76.43 & 13.35 & 2.44 & $<0.05$ \\
\hline & At 3 min & 70.27 & 8.37 & 74.8 & 12.67 & 1.63 & $>0.05$ \\
\hline & At $5 \mathrm{~min}$ & 72.17 & 7.29 & 74.5 & 10.17 & 1.02 & $>0.05$ \\
\hline & At $10 \mathrm{~min}$ & 74.87 & 7.04 & 75.1 & 10.24 & 0.1 & $>0.05$ \\
\hline & At $15 \mathrm{~min}$ & 76.87 & 6.93 & 74.23 & 7.25 & 1.44 & $>0.05$ \\
\hline & At $30 \mathrm{~min}$ & 76.13 & 4.64 & 73.8 & 5.24 & 1.82 & $>0.05$ \\
\hline
\end{tabular}

Table 2: Comparison of systolic blood pressure in study groups

\begin{tabular}{|c|c|c|c|c|c|c|c|}
\hline \multirow{2}{*}{\multicolumn{2}{|c|}{ SBP (mm Hg) }} & \multicolumn{2}{|c|}{ Group A $(\mathbf{n}=\mathbf{3 0})$} & \multicolumn{2}{|c|}{ Group B $(n=30)$} & \multirow[t]{2}{*}{ Z Value } & \multirow[t]{2}{*}{ P Value } \\
\hline & & Mean & SD & Mean & SD & & \\
\hline \multicolumn{2}{|c|}{ Baseline (T0) } & 124.23 & 9.87 & 123.83 & 13.53 & 0.13 & $>0.05$ \\
\hline \multicolumn{2}{|c|}{$\begin{array}{l}\text { Immediate after infusion of drug } \\
\text { (T1) }\end{array}$} & 115.77 & 9.81 & 121.43 & 11.56 & 2.04 & $<0.05$ \\
\hline \multicolumn{2}{|c|}{ After pre-medication (T2) } & 116.3 & 8.37 & 121.87 & 11.81 & 2.11 & $<0.05$ \\
\hline \multicolumn{2}{|c|}{ Pre intubation (T3) } & 112.83 & 10.11 & 119 & 13.25 & 2.03 & $<0.05$ \\
\hline \multirow{3}{*}{$\begin{array}{l}\text { Post } \\
\text { intubation }\end{array}$} & T4 (at $0 \mathrm{~min}$ ) & 118.8 & 9.47 & 124.93 & 10.26 & 2.41 & $<0.05$ \\
\hline & At 1 min & 114.1 & 10.49 & 120.53 & 9.74 & 2.46 & $<0.05$ \\
\hline & At $3 \mathrm{~min}$ & 106.6 & 9.43 & 110.3 & 9.87 & 1.48 & $>0.05$ \\
\hline
\end{tabular}




\begin{tabular}{|c|c|c|c|c|c|c|c|}
\hline & At 5 min & 103.43 & 9.96 & 107.93 & 9.94 & 1.75 & $>0.05$ \\
\cline { 2 - 8 } & At $10 \mathrm{~min}$ & 101.77 & 11.93 & 106.57 & 8.22 & 1.81 & $>0.05$ \\
\cline { 2 - 7 } & At $15 \mathrm{~min}$ & 98.4 & 10.93 & 104 & 7.95 & 2.27 & $<0.05$ \\
\cline { 2 - 8 } & At 30 min & 100.57 & 9.62 & 104.5 & 8.29 & 1.7 & $>0.05$ \\
\hline
\end{tabular}

Table 3: Comparison of diastolic blood pressure in study groups

\begin{tabular}{|c|c|c|c|c|c|c|c|}
\hline \multirow{2}{*}{\multicolumn{2}{|c|}{ DBP $(\mathbf{m}$}} & \multicolumn{2}{|c|}{ Group A $(\mathbf{n}=\mathbf{3 0})$} & \multicolumn{2}{|c|}{ Group B $(\mathbf{n}=\mathbf{3 0})$} & \multirow[t]{2}{*}{ Z Value } & \multirow{2}{*}{$\begin{array}{c}\mathbf{P} \\
\text { Value }\end{array}$} \\
\hline & & Mean & SD & Mean & SD & & \\
\hline \multicolumn{2}{|c|}{ Baseline (T0) } & 80.5 & 5.7 & 79.1 & 8.24 & 0.77 & $>0.05$ \\
\hline \multicolumn{2}{|c|}{$\begin{array}{l}\text { Immediate after infusion of drug } \\
\text { (T1) }\end{array}$} & 76.53 & 6.44 & 77.27 & 6.87 & 0.43 & $>0.05$ \\
\hline \multicolumn{2}{|c|}{ After pre-medication (T2) } & 72.8 & 8.47 & 78.03 & 12.3 & 1.92 & $>0.05$ \\
\hline \multicolumn{2}{|c|}{ Pre intubation (T3) } & 73.93 & 10.3 & 78.03 & 12.3 & 1.4 & $>0.05$ \\
\hline \multirow{7}{*}{$\begin{array}{l}\text { Post } \\
\text { intubation }\end{array}$} & $\mathrm{T} 4$ (at $0 \mathrm{~min}$ ) & 76.53 & 7.86 & 79.77 & 11.33 & 1.29 & $>0.05$ \\
\hline & At $1 \mathrm{~min}$ & 74.03 & 7.17 & 77.47 & 10.90 & 1.44 & $>0.05$ \\
\hline & At $3 \mathrm{~min}$ & 68.7 & 6.51 & 72.73 & 8.67 & 2.04 & $<0.05$ \\
\hline & At $5 \mathrm{~min}$ & 67.2 & 5.87 & 71.23 & 10.79 & 1.8 & $>0.05$ \\
\hline & At $10 \mathrm{~min}$ & 67.47 & 8.67 & 70.93 & 7.9 & 1.62 & $>0.05$ \\
\hline & At $15 \mathrm{~min}$ & 65.37 & 6.34 & 68.67 & 7.54 & 1.83 & $>0.05$ \\
\hline & At $30 \mathrm{~min}$ & 66.63 & 5.87 & 68.63 & 8.53 & 1.06 & $>0.05$ \\
\hline
\end{tabular}

Table 4: Comparison of MAP in study groups

\begin{tabular}{|c|c|c|c|c|c|c|c|}
\hline & MAP & \multicolumn{2}{|c|}{ Group A $(n=30)$} & \multicolumn{2}{|c|}{ Group B $(n=30)$} & \multirow[t]{2}{*}{ Z Value } & \multirow[t]{2}{*}{ P Value } \\
\hline & & Mean & SD & Mean & SD & & \\
\hline \multicolumn{2}{|c|}{ Baseline (T0) } & 95.23 & 6.81 & 94.63 & 11.17 & 0.25 & $>0.05$ \\
\hline \multicolumn{2}{|c|}{ Immediate after infusion of drug (T1) } & 89.63 & 6.84 & 92.4 & 7.99 & 1.44 & $>0.05$ \\
\hline \multicolumn{2}{|c|}{ After pre-medication (T2) } & 89.6 & 6.38 & 94.23 & 10.71 & 2.03 & $<0.05$ \\
\hline \multicolumn{2}{|c|}{ Pre intubation (T3) } & 86.5 & 9.35 & 92.3 & 12.2 & 2.06 & $<0.05$ \\
\hline \multirow{7}{*}{$\begin{array}{l}\text { Post } \\
\text { intubation }\end{array}$} & T4 (at $0 \mathrm{~min}$ ) & 91.56 & 8.24 & 95.4 & 10.63 & 1.56 & $>0.05$ \\
\hline & At $1 \mathrm{~min}$ & 87.2 & 7.42 & 91.7 & 9.58 & 2.05 & $<0.05$ \\
\hline & At $3 \mathrm{~min}$ & 81.8 & 6.06 & 85.87 & 8.94 & 2.06 & $<0.05$ \\
\hline & At $5 \mathrm{~min}$ & 80.3 & 6.64 & 84.67 & 8.86 & 2.16 & $<0.05$ \\
\hline & At $10 \mathrm{~min}$ & 79.2 & 9.62 & 83 & 6.8 & 1.77 & $>0.05$ \\
\hline & At $15 \mathrm{~min}$ & 76.73 & 7.77 & 80.67 & 7.56 & 1.99 & $>0.05$ \\
\hline & At $30 \mathrm{~min}$ & 77.8 & 7.05 & 81.4 & 8 & 1.85 & $>0.05$ \\
\hline
\end{tabular}

Table 5: Comparison of Aldrete score at end of surgery and $2 \mathrm{hrs}$ after surgery in study groups

\begin{tabular}{|l|c|c|c|c|c|c|}
\hline \multirow{2}{*}{ Aldrete score at } & \multicolumn{2}{|c|}{ Group A (n=30) } & \multicolumn{2}{c|}{ Group B $(\mathbf{n = 3 0})$} & \multirow{2}{*}{ Z Value } & \multirow{2}{*}{ P Value } \\
\cline { 2 - 5 } & Mean & SD & Mean & SD & & \\
\hline End of surgery & 8.47 & 0.57 & 8.93 & 0.52 & 3.27 & $<0.001$ \\
\hline 2 hrs after surgery & 9.87 & 0.35 & 9.93 & 0.25 & 0.85 & $>0.05$ \\
\hline
\end{tabular}

Table 6: Comparison of Brussel's score at end of surgery and $2 \mathrm{hrs}$ after surgery in study groups

\begin{tabular}{|l|c|c|c|c|c|c|}
\hline \multirow{2}{*}{ Brussels score at } & \multicolumn{2}{|c|}{ Group A $(\mathbf{n}=\mathbf{3 0})$} & \multicolumn{2}{c|}{ Group B $(\mathbf{n}=\mathbf{3 0})$} & \multirow{2}{*}{ Z Value } & \multirow{2}{*}{ P Value } \\
\cline { 2 - 7 } & Mean & SD & Mean & SD & & \\
\hline End of surgery & 3.9 & 0.4 & 4.13 & 0.35 & 2.37 & $<0.05$ \\
\hline 2 hrs after surgery & 4.87 & 0.35 & 4.9 & 0.31 & 0.39 & $>0.05$ \\
\hline
\end{tabular}


Bar Diagram 1: Comparison of aldrete score at end of surgery and $2 \mathrm{hrs}$ after surgery in group A \& group B

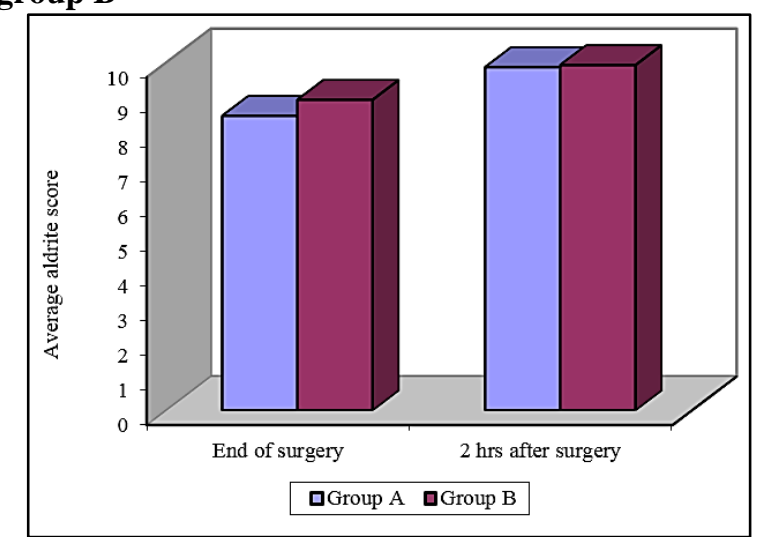

Bar diagram 2: Comparison of Brussel's score at end of surgery and $2 \mathrm{hrs}$ after surgery in group $\mathrm{A} \&$ group B

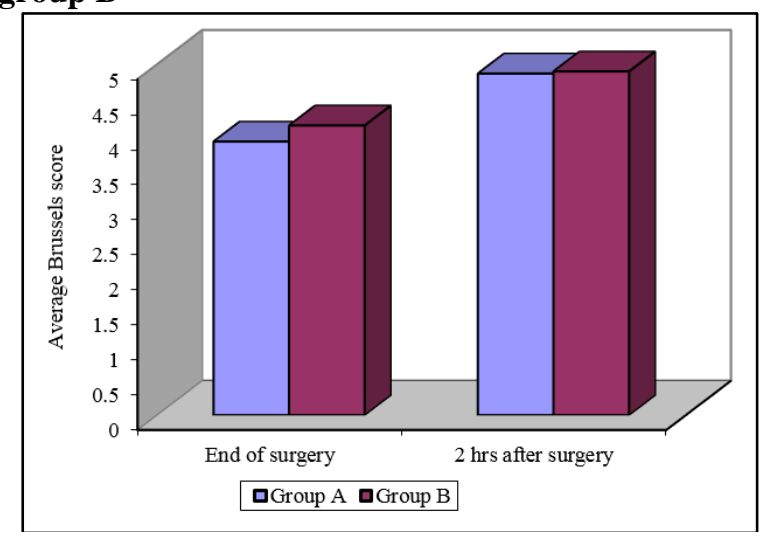

\section{Discussion}

The haemodynamic response to laryngoscopy and tracheal intubation has well been observed and studied over the years.

Many researchers have adopted various methods for attenuating the pressor response caused by laryngoscopy and tracheal intubation using, various inhalational and other pharmacological agents. ${ }^{4-8}$

In the recent decades several studies have focused on clonidine and recently on dexmedetomidine premedication to attenuate the haemodynamic responses following laryngoscopy and intubation. However there are very few comparative study. The present study is an attempt to fill the gap.

Alpha2-adrenoceptor agonists are being increasingly used in anaesthesia and critical care as they not only decrease sympathetic tone and attenuate the stress responses to anaesthesia and surgery; but also cause sedation and analgesia.

Alpha 2-adrenoreceptor agonist commonly used and studied are clonidine and dexmedetomidine.

Intravenous clonidine, is a centrally acting selective partial alpha 2-adrenergic agonist (220:1alpha 2 to alpha 1 affinity).
Clonidine stimulates alpha 2-adrenergic inhibitory neurons in the medullary vasomotor center and has sedative, analgesic, antihypertensive action in addition to reducing the anaesthetic drugs requirement. ${ }^{9-12}$

Dexmedetomidine, the other drug in our study is a highly selective, specific, and potent alpha 2 -adrenergic agonist (1,620:1 alpha 2 to alpha 1), especially for the alpha 2 A. Compared with clonidine it is eight times more selective for alpha 2. It attenuates haemodynamic responses to tracheal intubation, decrease plasma catecholamine concentration during anaesthesia and increases the likelihood of hypotension and bradycardia. The incidence of postoperative bradycardia has been reported as high as $40 \%$ in healthy surgical patients who received dexmedetomidine, especially high doses.

It provides anaesthetic sparing effects, anxiolysis, sedation and analgesia without respiratory depression. ${ }^{13}$ $-16$

In the current study we have used and compared the effectiveness of a pre-induction dose of clonidine $4 \mathrm{mcg} / \mathrm{kg}$ with dexmedetomidine $1 \mathrm{mcg} / \mathrm{kg}$ infused intravenously 15 mins prior to induction over a period of 10 minsinattenuating the haemodynamic stress responses resulting from laryngoscopy and endotracheal intubation.

There is wide variation in the effective dose of clonidine required to attenuate the stress response from $2 \mathrm{mcg} / \mathrm{kg}$ to $8 \mathrm{mcg} / \mathrm{kg}$ by different authors in their respective studies.

Tripathi et al $^{17}$ and Mondal $\mathrm{S}$ et $\mathrm{al}^{19}$ have used clonidine $2 \mathrm{mcg} / \mathrm{kg}$ in there respective studies, Ray M et $\mathrm{al}^{11}$ and Arindam et $\mathrm{al}^{18}$ have used clonidine 3 $\mathrm{mcg} / \mathrm{kg}$, while Kulka PJ et al. ${ }^{12}$ have concluded clonidine $4 \mathrm{mcg} / \mathrm{kg}$ as the effective dose.

Based on the observations and results in these studies, we have decided to use $4 \mathrm{mcg} / \mathrm{kg}$ of intravenous clonidine as the effective dose in our study.

As compared to clonidine there is not much variation in the dose of dexmedetomidine. In most of the studies dexmedetomidine has been used in the dose of $1 \mathrm{mcg} / \mathrm{kg}$ intravenously, so we have used the same dose in our study. ${ }^{20-23}$

Varshali et al, ${ }^{20}$ Bajwa SS. et $\mathrm{al}^{21}$ and Srivastava et al ${ }^{22}$ observed that Dexmedetomidine, $1 \mathrm{mcg} / \mathrm{kg}$ while Sebastian B et $\mathrm{al}^{23}$ found dexmedetomidine $0.75 \mathrm{mcg}$ $/ \mathrm{kg}$ effectively attenuates sympathoadrenal response to tracheal intubation.

In the current study Haemodynamic parameters Heart rate, S.B.P, D.B.P, M.B.P were analyzed and recorded quantitatively within groups for each stage from preoperative period to 30 mins post - intubation period.

Mean heart rate showed fall following administration of study drug which was not significant statistically in both the groups ( $p>0.05)$.

Fall in the heart rate seen following dexmedetomidine or clonidine loading infusion was 
$19 \%$ and $23 \%$ respectively from the baseline which was clinically significant in clonidine group but was statistically not significant in both the groups ( $p>0.05$ ).

Both dexmedetomidine and clonidine groups showed increase in Mean heart rate following intubation, $8 \%$ and $10 \%$ respectively. (Table 1)

In the current study, Mean Systolic, Diastolic and Mean arterial blood pressure showed fall in Group A as well as in Group B, following infusion of study drug and fall in the Mean pressures seen in Group B were comparatively less than in Group A.

There was a transient increase in the Mean systolic, Diastolic and Mean arterial pressure following laryngoscopy and tracheal intubation in Group A as well as Group B.

Arindam et al $^{18}$ conducted a similar comparative study between clonidine $(3 \mathrm{mcg} / \mathrm{kg} / \mathrm{min})$ and dexmedetomidine $(0.5 \mathrm{mcg} / \mathrm{kg} / \mathrm{min})$ intravenous infusion for attenuation of pressor response, and found that attenuating response to hemodynamic changes were observed with both drugs.

Mondal S et a $1^{19}$ conducted a similar comparative study between clonidine $(2 \mathrm{mcg} / \mathrm{kg})$ and dexmedetomidine $(1 \mathrm{mcg} / \mathrm{kg})$ and found that dexmedetomidine blunted the hemodynamic responses more than clonidine or placebo.

Srivastava, et al ${ }^{22}$ conducted a comparative study and found dexmedetomidine $1 \mathrm{mcg} / \mathrm{kg}$ to be more effective than esmolol $1.5 \mathrm{mg} / \mathrm{kg}$.

Ray $\mathrm{M}$ et $\mathrm{al}^{11}$ conducted a study and concluded that $3 \mu \mathrm{g} / \mathrm{kg}$ of clonidine attenuated the haemodynamic response to tracheal intubation and they reduced the propofol and fentanyl requirement significantly.

The present study findings corroborate with those of previous studies. Similar to our study, where in there was fall in the heart rate by $19 \%$ and $23 \%$ of the baseline respectively in dexmedetomidine and clonidine group, even in the above mentioned studies there was similar fall in the heart rate. In our study 2 patients in dexmedetomidine group and 3 patients in clonidine group developed bradycardia, a possible consequence of administration of $\alpha_{2}$ agonist which promptly responded to inj. atropine $300 \mathrm{mcg}$ intravenously. No significant fall in blood pressure was observed in either of the patient groups. There was no case of awareness suggesting adequate depth of anaesthesia.

Similar to our studies, there was fall in the S.B.P, D.B.P and M.A.P following infusion of drug, in the above mentioned studies.

Following intubation average increase in heart rate was $8 \%$ and $10 \%$ respectively in the dexmedetomidine and clonidine groups.

Following tracheal intubation, maximal average increase was 5\% in systolic and 3\% in diastolic blood pressure in dexmedetomidine group, as compared to $6 \%$ and $4 \%$, respectively, in the clonidine group.

There was a significant attenuation of heart rate and blood pressure in both the groups. The pulse rate was significantly reduced with both the drugs, and both the drugs showed mild reduction in blood pressure.

The above haemodynamic parameters shows significant attenuation of pressor response following laryngoscopy and tracheal intubation in our study.

In our study Isoflurane consumption, propofol requirement and opioid requirement throughout the intraoperative period was reduced in both the Groups, which is in accordance with the findings by Ray $\mathrm{M}$ et al, ${ }^{11}$ Mondal S et al. ${ }^{19}$ Varshali et $\mathrm{al}^{20}$ and Bajwa SS et al. $^{21}$

Aldrete recovery score $^{24}$ and Brussels sedation score $^{25}$ were calculated and recorded at the end of surgery, and two hours after surgery in recovery room to assess the recovery of patients.

Scores were not significant clinically and were better in group B as compared to group A.

Patients were sedated but arousable in both the group, in the immediate post operative period. The duration of recovery was similar in both the groups.

Recovery and Sedation scores have been used by various authors in several similar studies on dexmedetomidine and clonidine, with similar findings. ${ }^{19-21,23}$

\section{Limitation of Study}

More studies with larger sample size are required to establish the effects of continuous intravenous infusion of dexmedetomidine and clonidine throughout the intraoperative period, on anaesthetic requirements, haemodynamic parameters and recovery profile of the patients.

Plasma catecholamine level monitoring was not performed.

Invasive blood pressure monitoring was not used which would have provided continuous, real -time haemodynamic monitoring. This was not performed due to cost constraints.

\section{Conclusion}

Based on our study we conclude that:

1. Both clonidine and dexmedetomidine attenuates hemodynamic responses to tracheal intubation, decreases plasma catecholamine concentration during anaesthesia, decreases perioperative requirements for inhaled anaesthetics and opioids.

2. Both the study drugs provided adequate sedation as well as analgesia, and early recovery of the patients in the post-operative period.

3. No adverse cardiovascular effects from the drug were seen in the present study. Bradycardia, a possible consequence of administration of $\alpha_{2}$ agonist, can be counteracted by the use of atropine. 


\section{References}

1. Stoelting RK. Circulatory Changes during Laryngoscopy and Tracheal Intubation: Influence of Duration of Laryngoscopy With or Without Lidocaine. Anaesthesiology. 1977;47:381-841.

2. Fox EJ, Sklar GS, Hill CH. Complications Related to Pressor Response to Endotracheal Intubation. Anaesthesiology. 1977;47:524-25.

3. Shribman AJ, Smith G, Achola KJ. Cardiovascular and catecholamine responses to laryngoscopy with and without tracheal intubation. Br J Anaesth. 1987;59:295-9.

4. Stoelting RK. Attenuation of blood pressure response to laryngoscopy and tracheal intubation with Sodium Nitroprusside. Anesthesia Analgesia. 1979;58:116-9.

5. Scheinin B, Scheinin M, Vuorinen J. Al fentanyl obtunds the cardiovascular and sympathoadrenal responses to suxamethonium facilitated laryngoscopy and intubation. British Journal of Anaesthesia. 1989;62(4):385-93.

6. Kay B, Healy TEJ, Bolder PM. Blocking the circulatory responses to tracheal intubation, a comparision of Fentanyl and Nalbuphine. Anaesthesia. 1985;40:960-3.

7. Fuji Y, Tanaka H, Saitoh Y, Toyooka H. Effects of Calcium channel blockers on circulatory response to tracheal intubation in hypertensive patients: Nicardipine vs Diltiazem. Canadian Journal of Anaesthesia.1995;42:785-8.

8. Nishikawa T, Naiki A. Attenuation of the pressor response to laryngoscopy and tracheal intubation with I.V. Verapamil. Acta Anaesthesiol Scand.1989;33:232-5.

9. Stoelting RK. Pharmacology and Physiology in anaesthetic practice". $4^{\text {th }}$ ed. Philadelphia: Lippincott; 2006.340-4.

10. Aantaa R, Scheinin M. Alpha 2-adrenergic agents in anaesthesia. Acta Anaesthesiol Scand. 1993;37(5):433-48.

11. Ray M, Bhattacharjee DP, Hajra B, Pal R. Effect of clonidine and magnesium sulphate on anaesthetic consumption, haemo dynamics and post operative recovery : A comparative study. Indian Journal of Anaesthesia. 2010;54(2):137-41.

12. Kulka PJ, Tryba M, Zenz M. Dose-response effects of intravenous clonidine on stress response during induction of anaesthesia in coronary artery by pass graft patients. Anaesthesia Analgesia.1995;80:263-8.

13. Virtanen R, Savola JM, Saano V, Nyman L. Characterization of the selectivity, specifi city and potency of medetomidine as an alpha 2-adrenoceptor agonist. Eur J Pharmacol. 1988;150(1-2):9-14.

14. Scheinin H, Virtanen R, MacDonald E, Lammintausta R, Scheinin M. Medetomidine - a novel alpha 2adrenoceptor agonist: a review of its pharmacodynamic effects. Prog Neuropsychopharmacol Biol Psychiatry. 1989;13(5):635-51.

15. Keith A, Sergio D, Paula M, Marc A, Wisemandle W, Alex Y. Monitored anesthesia care with dexmedetomidine: a prospective, randomized, doubleblind, multicenter trial. Anesth Analg. 2010;110:47-56.

16. Paranjpe JS. Dexmedetomidine: Expanding role in anesthesia. Med J DY Patil Univ. 2013;6:5-13.
17. Tripathi DC, Shah TS, Dubey SR, Doshi SM, Raval PV. Hemodynamic stress response during laproscopic cholecystectomy: Effect of two different doses of intravenous clonidine premedication. Journal of Anaesthesiology and Clinical Pharmacology. 2011;27:475-80.

18. Arindam S. Comparison of effects of intravenous clonidine and dexmedetomidine for blunting pressor response during laryngoscopy and tracheal intubation: A randomized control study. Anesth Essays Res. 2014;8(3):361-66.

19. Mondal S. Comparison of dexmedetomidine and clonidine for attenuation of sympathoadrenal responses and anesthetic requirements to laryngoscopy and endotracheal intubation. International Journal of Basic and Clinical Pharmacology. 2014;3(3):501-06.

20. Varshali MK, Sushma L, Ramesh N. Dexmedetomidine attenuates sympathoadrenal response to tracheal intubation and reduces perioperative anaesthetic requirement. Indian Journal of Anaesthesia. 2011;55(4):352-7.

21. Bajwa SS, Kaur J, Singh A, Parmar SS, Singh G, Kulshrestha A, Gupta S, Sharma V, Panda A. Attenuation of pressor response and dose sparing of opioids and anaesthetics with pre-operative dexmedetomidine. Indian Journal of Anaesthesiology. 2012;56:123-8.

22. Srivastava. "Comparative evaluation of esmolol and dexmedetomidine for attenuation of sympathomimetic responses to laryngoscopy and intubation in neurosurgical patients. Journal of Anaesthesiology Clinical Pharmacology. 2015;31:186-90.

23. Sebastian B. Attenuation of hemodynamic responses to laryngoscopy and endotracheal intubation with intravenous dexmedetomidine: A comparison between two doses. Indian J Anaesth. 2017;61:48-54.

24. Phillips NM, Haesler E, Street M, Kent B. Post anaesthetic discharge scoring criteria systematic review. JBI Library of Systematic Reviews. 2011;9(41):16791713.

25. Detriche O, Berre A, Masaut J, Vincent JL. The Brussel's sedation scale. British Journal of Anaesthesia. 1999;83(5):698-701.

How to cite this article: Suryawanshi CM,
Kumar R, Wadhwa R. A prospective study
comparing the efficacy of intravenous clonidine
with intravenous dexmedetomidine in
attenuating the haemodynamic stress response
during laryngoscopy and endotracheal
intubation. Indian J Clin Anaesth.
2018;5(3):327-333.

